\title{
GODFREY HAROLD HARDY
}

\section{7-1947}

Last year English mathematics suffered the loss of that mathematician who has more than any other been identified with the English School from the early 1900s to the present.

Godfrey Harold Hardy died of heart failure in 1947. For a considerable period his work had been restricted by bad health, which came as a special misfortune to a man whose career for many years had been identified not only with great mental activity, but also with a large measure of interest in all those games in which a ball takes part, and for whom this interest involved a very considerable share of personal participation. He was an encyclopedia of information concerning cricket, and to the very end nothing delighted him more than to witness a match.

Hardy came from a family with artistic and intellectual traditions. He went to Winchester and then to Trinity College, Cambridge. The milieu in which he developed as a mathematician is one which it is particularly difficult for those outside of the English tradition to understand, and even rather difficult for those belonging to the newer English tradition which Hardy himself had so much hand in establishing.

It all goes back to the disputes between Newton and Leibniz concerning the invention of the calculus. At present we have not much doubt of the fact that Newton invented the differential and integral calculus, that Leibniz' work was somewhat later but independent, and that Leibniz' notation was far superior to Newton's. At the beginning the relations between the Leibnizian and the Newtonian schools were not hostile, but it was not long before patriotic and misguidedly loyal colleagues of both discoverers instigated a quarrel, the effects of which have scarcely yet died out. In particular, it became an act of faith and of patriotic loyalty for the British mathematicians to use the less flexible Newtonian notation and to affect to look down on the new work done by the Leibnizian school on the Continent. For a while there was no scarcity of able English mathematicians of the strictly Newtonian school. For example, we must mention Taylor and Maclaurin. However, when the great continental school of the Bernoullis and Euler arose (not to mention Lagrange and Laplace who came later) there were no men of comparable calibre north of the Channel to compete with them on anything like a plane of equality. Part of this must be attributed to the fallen status 
of the English Universities during the 18th century. In the 17th century the English Universities were seats of learning comparable with the greatest schools of the Continent, but in the 18th century the grasping new Whig aristocracy that had risen out of the prosperous middle class (the nabobs) took over the older English institutions, the common land, public schools, universities, lock, stock and barrel, as their private property. The public schools were transformed from institutions of a semi-charitable nature to the place where the children of the new aristocracy were formed after its own pattern. The universities became nests of sinecures for dependent clergymen. In this atmosphere creative scholarship did not and could not flourish, and it is not until the 19th century is well under way that we find the signs of a new awareness of what the continental scholars, particularly Laplace and Lagrange, had done in mathematics. Among the English names belonging to this tentative reformation we may mention Boole, Peacock and DeMorgan. DeMorgan in particular is associated with the new University College at London which by its pressure did so much to bring the older universities back to a sense of intellectual responsibility.

This reform of English education was far from complete. The level of mathematics at Oxford was for many years scarcely more than contemptible, and even at Cambridge the training was devoted to the passing of severe examinations, the Triposes, rather than to the development of original mathematical workers. What mathematical talent there was in the British Isles went rather to the formation of a great school of mathematical physicists. Even here Cambridge entered the game rather late. Clerk Maxwell owes more to Faraday, the self-taught practical experimentor, than to any Cambridge man, and neither George Green nor Hamilton was in the Cambridge tradition. Sylvester, as a Jew, was not permitted to enter the older universities till towards the end of his life, and is another of those seminal figures who center around the University of London. Cayley is the first real great Cambridge pure mathematician of the 19th century. He certainly was in touch with those continental scholars whose interest was primarily in algebra, but algebra was at that time an important secondary mathematical subject rather than one in the main stream of development.

It is not remarkable that in such an environment, secluded from the central activity of world mathematics, mathematical study should be devoted rather to the formation of public school ushers or a trial intellectual run for promising barristers than to research activities. As a matter of fact, the Tripos was made such an ordeal, at least in diffi- 
culty though in general not in originality, that it marked the culminating point in the intellectual life of many of those who participated in it, and their subsequent activity became retrospective rather than creative.

This was the state of English mathematics to about the turn of the century, when an awareness of the great work of the continental mathematicians smuggles itself into England by non-academic bypaths. The English generation of pure mathematicians of the 19th century and the first decade of the 20th century is curiously tentative. It has many important names, such as A. N. Whitehead, Andrew Forsyth, E. A. Hobson and W. H. Young. These all carry to some degree a mathematical style and ethos formed under the older English tradition into a period when the topics of interest were far more continental.

Whitehead developed the new stream of postulationalism into a tool for handling the problems of multiple algebra. Together with Bertrand Russell he formed the incipient mathematical logic of Boole and of Frege into something much more scholarly and complete. Nevertheless, he did not quite arrive at the present expanded technique for handling questions of modern algebra and of topology for which he paved the way, and his later career suggests a definite abandonment of mathematics for metaphysics.

Forsyth wrote several extremely inadequate books on the theory of functions and on differential equations, but their inadequacy must not obscure the fact that they represent a transfer of English mathematical interest to problems significant to the contemporary French and Germans. Hobson, after an initial career in the classical British tradition, shifted his interest to the new theories of the integration of Lebesgue, and published a book which is a tour de force of the correct use of the modern notions, although the whole feeling of the book belongs to earlier days. Before this W. H. Young had almost shared with the Frenchman-Lebesgue the honors of inventing the new theory of integration, for which he lost much of the contemporary credit through a certain difficulty of style and through personal idiosyncrasies.

It was into this environment of transition that Hardy and his immediate associates were born as scientists. They represent the first generation to have had contact from the beginning of their training with modern continental analysis and point-set theory. They also represent the first generation, unless one makes a partial exception here of Professor Young, to have familiar personal contact with all the leaders of their work on the continent and to be regarded by the latter as friendly equals. 
Their students, and this is particularly the case with Professor Hardy, are scattered over the whole world. I need only mention Vigayaraghavan, and especially the late mathematician Ramanujan of India, Hua Loo Keng of China, Bohr of Denmark, Landau and Heilbronn of Germany, Levinson, Widder and the reviewer himself from the United States, and there are many others whom I could add.

While it was a great achievement to accomplish the integration of British mathematics into world mathematics it would not alone have placed Hardy where he stands if it were not for certain more intellectual personal characteristics.

In the first place, Hardy's approach to mathematics was that of a sportsman. To be a sportsman means to take a joy in difficulty, and to overcome difficulties according to a meticulously exact code of what is permissible and what is not permissible.

Hardy chose as his field the analytic theory of numbers, in which the theory of the Riemann zeta function had been developed sufficiently to make the field promising, and in which important triumphs had already been achieved by de La Vallée Poussin and Hadamard, but where the greater part of the more precise results remained wideopen to speculation. In the closely related field of Waring's problem, the problem of the representation of all numbers by the sum of a fixed number of $n$th powers, Hilbert had already obtained important results with the aid of a method distinctly algebraic rather than analytic. In those fields Hardy and his colleague, Littlewood, showed a virtuosity of rigorous mathematical technique which led to the solution of wide classes of problems. That these methods have been supplemented and in many cases superseded by the work of Vinogradov and his school in no way detracts from the subtlety and the power of the methods of the English school.

Your true sportsman is always a little aloof from worldly matters. He prefers the skilful use of a tennis racquet to the skilful use of an axe. In this respect Hardy is true to form. How much of the emotional response which led him to become a conscientious objector in the first World War is due to the abhorrence of the social destructiveness of war itself and how much to his feeling of the perversion of a beautiful thing like mathematics to unworthy ends one cannot say. Perhaps the two motives are not fully distinct. It is, however, certain that Hardy carried his hostility to applied mathematics to the extent of a real doubt that much work, which attached itself to his own but claimed an engineering motivation, really was genuinely associated with engineering.

Besides the foreign scholars whom we have listed, Hardy was a great teacher and a fellow worker of the younger leaders of English 
mathematics. It may not be fair to call Littlewood his pupil, but it is certainly fair to attribute to the collaboration between the two much of the stimulus which led Littlewood to develop his own vein. This vein is so closely related to Hardy's that it may be difficult for those not thoroughly familiar with the work of both to separate them. I think it is fair to say that throughout their long collaboration the extremes of technical facility belong to Littlewood, but that much of the nexus of leading ideas and the philosophical unity is that of Hardy.

If I were to single out any of the English disciples of those two men as the continuers of their tradition I should name Titchmarsh, Ingham and Paley. In his early twenties Paley had already distinguished himself as sharing with Littlewood some of the latter's power and virtuosity. His early death in a skiing accident in the Canadian Rockies was a tragedy which has been felt in the entire later development, not only of English, but of world mathematics.

The Hardy school came into being in a time of mathematical transition, not only in England but elsewhere. In the period between the wars there were signs of another change of interest which was felt all over the world, but perhaps most intensely in the United States. It presented on the one hand something of which Hardy would thoroughly approve, namely, the separation between pure and applied mathematics; on the other hand, largely under the influence of Veblen, the development of topological and algebraic fields led to somewhat a cavalier assumption that the days of analysis were over. The dominance of the Princeton school over the many English scholars who have studied there has carried these new movements back to England. I need not mention the younger Whitehead, Newman, Hodge and Mordell to indicate the trend. Indeed, Mordell, who like Hardy is a number-theory man but unlike Hardy thinks much more in algebraico-geometrical terms, is Hardy's successor.

How long these new interests will hold the upper hand is no man's prediction. I myself do not share the easy assumption that analysis is played out, and I believe that if Paley had lived these algebraic and topological schools would still find a serious competitor along the lines of Hardy's analysis. I think, however, that Hardy's opposition to applied mathematics might well give way to a recognition of the important pure mathematical problems presented by applications.

Here a parenthetic remark is permissible. The extreme abstractness of some of the modern schools tends to become rather empty abstractness unless it is supplemented by a study of special cases where the difficulty is found to be a real difficulty even when the abstract problem is studied in a concrete case. There is nothing better 
than concrete instances for the morale of the mathematician. Some of these concrete cases are to be found in mathematical physics and the closely related mathematical engineering, but there is a branch within mathematics which has similar merits as a source of actual problems. This field is that of number theory. It is here that such concrete cases arise with the greatest frequency and where very precise problems which are easy to formulate may demand the mathematician's greatest power and skill to resolve. Here Hardy found the central core of his work. It is precisely because Hardy's analytical tools are applied to number theory that his work has a freshness and exactness which much, although by no means all, of the fashionable work of the present day fails to exhibit. In short, Hardy had his feet on the ground.

In addition to his accomplishments in research and teaching, Hardy contributed greatly to the reform of mathematical instruction. He was bitterly opposed to the rigid and unmathematical Tripos system and is unquestionably in a large part responsible for the fact that the order of rank of the Wranglers, those who obtain first class in the Tripos, has not been published since 1912. The present mathematical Tripos and indeed the whole system of training at Cambridge has been modified in the sense of conforming very closely to the actual work and career of the mathematicians of this day. Even this change, which has spread from Cambridge to all the British Universities, is a compromise between the old system and a system where research should even more completely take the place of examinations.

Hardy accepted the shift of the focus of modern interest away from his own fields with resignation, and yet with a certain sadness. He regarded it as inevitable, and still he felt that with this inevitable change his own day was done. There is much of this sadness in the book which he published under the title $A$ mathematician's apology.

Hardy was a staunch friend of all mathernaticians, and especially of all young mathematicians. There is no man to whom so many of us owe so much personally. His loss, although we had been prepared for it for some years, gave us a real shock, and brought us the sense of the passing of a great age.

NORBERT WIENER 